\title{
THE PHYSICAL AND SOCIAL ASPECTS OF THE HUMAN BODY AS A REAGENT FOR THE CONSUMPTION
}

\author{
V.Stanev* \\ Department of Marketing and International Economic Relations, Faculty of Economic and Social \\ Sciences, Plovdiv University "Paisii Hilendarski", Plovdiv, Bulgaria
}

\begin{abstract}
Two consecutive texts consider the question of the human body with its natural and interdependent entities - physical and social, as a reagent of the consumption. The first paper highlighted the sociocultural and economic characteristics of modern consumption, and this one will consider the relationship between the physical and social sides of the human body and its market aspects and dimensions, and their impact on the appearance and the growth of the new industries.
\end{abstract}

Key words: human body, consumption, market aspects.

The preceding article examined some of the most prominent dominants in the behaviour and consumption of postmodern man, established the link between consumption, behaviour and the physiological basics of our body, referring also to the exploitation of the body as a means of attaining social and economical goals, substantiated its 'binary' constitution - the physical body created by nature and typified with the specific features of the society, and its the social manifestation created by society. In order to shift the focus from the physical body and its referent market to its social counterpart, it is necessary to take account of some of today's cornerstone mass culture imperatives having direct impact on consumption.

\section{Mass culture and its consumer dominants}

One of most apparent features of the present day is that mass communication channels incite mass demands which society is unable to meet accordingly. Life forks into work - the resource, and entertainment - the goal, whereas entertainment and personal experience pertain entirely to free time. Vacation has turned into a pursuit of something exciting that will compensate the monotony of working

\footnotetext{
*Correspondence to: Velin Stanev, Department of Marketing and International Economic Relations, Faculty of Economic and Social Sciences, Plovdiv University "Paisii Hilendarski", Plovdiv 4000, Bulgaria, 24 Tsar Asen St., GSM: +359 8882939 13,E-mail:velstan@yahoo.com
}

routine, while the cultural participation is tied down to watching the TV screen or the computer monitor. The formula used by the global postmodern mass culture to obsess through mass media is the formula of the spectacle.

Serious audiovisual programme formats (popular, observational, science-fiction, debates, commentaries, documentaries) and even news bulletins with their composition, internal structure, dynamics and audiovisual complexity are designed and presented as a spectacle, very much like the schedules of popular science fiction channels where programmes have long since been directed as "outrageous" suspense thrillers. The nature of spectacle is implied in the tendency of mass culture to seek greater thrill and amusement as an antidote of boredom. In fact, postmodern mass culture has emerged and flourished with the rise of mass boredom which, until then, has been a privilege available only to the social elite. But while traditional boredom is caused by the monotony of routine life which can be successfully overcome by entertainment, the new boredom of postmodern man is permanently felt as alienation, weariness, lack of concern and lack of interest - faculties which the individual relieves by utilizing compensatory behaviors. Thus, the range of professions becomes more and more diverse while the sources of entertainment become more uniform. Certain models of entertainment are adopted as a standard which soon turns 
mass amusement into a herd instinct, and alas, to another boredom (1).

Postmodern mass culture is an ideology of happiness whose benchmark is the individual who seeks self-realization and fulfillment through the reception of his social body, love and material well-being as dividends. Conceived early in the period between the two world wars and undergoing impressive progress in postmodernity, the myth of personal happiness is the most overwhelming myth of contemporary consumer society. Forgetting the Divine origin and the cosmic order of the universe, man has also consigned to oblivion the tragic of his short earthly life and the bliss promised after death.

Asceticism and naked shame are relics to a bygone past. Man wants to and must be happy here and now - for living itself. This heavenly life mushrooms with the development of technologies because they broaden individual choice and enhance highly customized production and consumption. Everybody is free to choose where to live, how to live, who to live with, what to religion to believe in, even what gender identity to express - freedoms that were rationed or stigmatized only a century ago. The maxim "I decide who I am" is related with the postmodern collapse of the gravity of life and mass media, to a large extent, exerts a controlling influence on such choices, especially life style media - the all-knowing consumer guides whose function varies from giving instructions about how to wash one's teeth to how to live one's life. For centuries on end, making the right choice has been a struggle. In postmodern times, it is no longer a burden.

The idea of happiness, however, vary greatly by civilizations and has different dimensions even within one and the same culture. In its latest version, men and women alike want to be eternally young (spiritually and physically) and enjoy living the present moment. The emotional values are the vigorous body (youth), love, adventure and family life. Material values are possession and consumption. The link is successful career the social promotion and recognition as a result of successful adaptation of the individual to the systems of social values.

The problem is mortality. Man lives with the assumption of being unique and immortal, but falls victim to his short earthly life. Entertaining mass culture formats and fixation on physical youth and beauty serve as a compensatory mechanism. Comedies ignore the global tragic perspective of life. The focus is on singularity in all forms of humor, even when it is completely shallow. Furthermore, there is a general tendency to debunk serious attitude which results in the end of heroism and increase of individual self-worth as being more important than anything else that requires selfsacrifice. European culture has been a culture of heroism and heroes who sacrifice their lives in the name of values and ideas. Nowadays, life is a game dictating the rules of our behaviour. Nothing is more serious than the game itself and every idea can be held up as an object of ridicule, including the drama of history.

Postmodern times bring yet another brand new sensation - anyone can be a star. Celebrities, being undoubtedly the most interesting of the three general types of public figures - heroes, quasars, celebrities - are an amalgam between fiction and reality. Their immortality sublimates in an illusionary blending of fictional and real but their tragedy is in the resolute deprivation of private life (it is in the public domain), in the loss of anonymity, intimacy and biographical identity. Unlike the case with Marilyn Monroe where fiction and biography go hand in hand and tabloids mythologize chronicles based on relation and analogy, Madonna (for example) is entirely a product of persuasive communication. Her biography is structured as a mosaic so as to follow fictional patterns. As if the constant identity of the real individual is elaborately customized to become a product for manipulation so that it can actually fit into the image of the manipulation product. Girl and boy bands (Take That, Backstreet Boys, Spice Girls, Blue, t.A.T.u.), are designed with biography portrayal preceding the actual "invention" of the singers. In this way celebrities become a vehicle of a preconceived biographical project implanted to their real self. In the same time, the myth of personal happiness is attainable through identification with the celebrities of the media, which might as well be the new Mount Olympus. Since every story is a story of an ordinary girl or an ordinary boy, the myth of personal happiness becomes attainable for everyone. Olympus is an open door and everyone is invited. Yet, in order to become a real celebrity some effort, good luck and a big break are required and in postmodern times, identification with celebrities yields to demythologization. The new credo is "I am the celebrity" or "why should I be like celebrities - I want celebrities to be like me". Reality formats make celebrities out of ordinary people whose celebrity status has been acquired through 
exposing their body and soul pixelated in the public domain.

Paparazzi voyeurism shows that celebrities are like any other people and might as well get drunk, vomit, rush to the toilet, get sick and feel pain.

\section{The social body and consumption}

The human body is valued by all societies primarily as a work force (to produce goods and services). Associating with society means labour, labour demands consumption which provides for the reproduction of the work force, whereas different types of labour create various needs for reproduction. Heavy physical work or working under unfavorable weather conditions requires sustaining food, warm clothes protect the body from the cold, responsible positions involve special distribution of responsibilities, and imply physical and mental health. This is how the structure of social production dictates the structure of the needs of our body, whereas the consumption that sustains this body function coincides significantly with the "function from on high" - health maintenance. The body is not solely a work force, however. It is a communication channel for symbolic interaction with other people and this intentional social communication dictates a rather different consumption. Beauty can be analyzed as an exchange of symbolic content which functions as a symbolic value (2). In other words, human body is both a social construct and a fact of culture, provided that

- every culture involves imposing body standards (of beauty, attractiveness, ugliness);

- the body holder adjust it to the established standards (through bodybuilding, physical exercise, cosmetics, plastic surgery).

Human body is also a communication channel by which the body holder transmits information about himself to stimulate (or modify) the recipient behaviour. Man comes forth to the world and his social environment represented directly by his body (or body parts) or its image 1 . The need of depicting visual appearance for presentation purposes has been met by the development of portrait painting, photography and film industry together with all of its adjoining goods and services. But if after antiquity the object of

\footnotetext{
${ }^{1}$ Such images refer to a much broader concept that just the selfie image that became outrageously popular in the recent years. In fact, long before the discovery of photography and the mania for compiling family albums, art has served as a means of presentation, then and there, or as a record for future decedents.
}

depiction is the entire body (clad in clothes) or the face, which is freely manifested in most cultures, there are no taboos and restrictions pertaining to current times and mores. Even contemporary advertising subjected to its laws and codes picks out and objectifies every single body part (including feet, neck, face, hands, ankles, breasts, etc.)

In order to perform its function as a means of symbolic social interaction, the perceived needs of the social body are the motivating factors of behaviour (including consumer behaviour). The absolute minimum for normal communication is that bodies should not elicit a sensation of disgust ${ }^{2}$. Impure body or its impure parts may be interpreted as conflicting the established cultural norms and often elicit (often erroneously) disposition to infringe other cultural norms. Keeping the body clean and well-groomed has developed into a consciously designed symbol which signifies engagement to a particular culture. This perceived need has created the colossal and constantly growing global market of hygiene products. The concept of clean body is, however, rather tentative. It corresponds to the norms of the respective culture which are unceasingly developed, changed and modernized with the progress of technologies, especially in the times of mass cultural globalization. Norms are indicative of the receptive and generative potential of society this is why the perception of pure and impure body varies by societies (and by the stages of development of one and the same society). The conditions for maintaining personal hygiene in medieval Europe were highly limited, moreover, those limitations were vindicated by the medical beliefs of the time degenerating washing, cleaning and bathing as sinful treatments which eroded the body and transmitted diseases. Wealthy people made no exception and reduced personal hygiene to (comparatively) frequent change of underwear and bed linen, combined with lavish use of fragrances, which in turn encouraged the boost of perfume industry as a washing alternative ${ }^{3}$. Even in the late $19^{\text {th }}$ century, bathrooms inside the bourgeois buildings of the big cities in

\footnotetext{
${ }^{2}$ In the context of European culture, personal hygiene is a practice connected also with health maintenance. ${ }^{3}$ King Louis XIV ("Sun King") is said to have only bathed three times in his lifetime - at his birthday, the day he was baptized and at before his funeral. And Elisabeth Petrovna, the Russian Empress, known for her faultless cleanness had baths once per month. Even a passing glance on the habits of tough men of the Wild West is enough to reveal that bathing and changing underwear (should there be any spare pair of underwear, of course) was reduced to a short visit to the local whorehouse after several weeks of herding cattle.
} 
USA, the land of unlimited possibilities, were a rarity. The first building equipped with bathrooms was built in Boston in 1829. It was only that it had 170 rooms and just 8 bathrooms. The first residential homes with inside bathrooms appeared in 1932 (3,174). It is a fact that by raising the awareness of the advantages of maintaining a clean body, the sanitary standards in home design have changed accordingly. Until the 70s, public baths were normal practice in Bulgaria, while private bathrooms - a luxury. The cultural norm of the frequency of full body wash used to be once per week. Prefab apartment buildings (now stigmatized as a towering reminder of the Communist era) equipped with private bathrooms reformed the standard hygiene norm and, respectively, the consumption of hygiene products. Hence, private bathrooms became a must for the real estate market and for hotel accommodation facilities - an outright example of market situations based on a new structure of perceived needs.

Body takes the leading role in communication and social convergence. Physical appearance corresponding to the existing cultural-specific standards of beauty is perceived as sexually attractive, thereby increasing the chances of finding a partner and raising a family. Striving to achieve the established standards of beauty is universal and inherent to every epoch. Physical exercise in Ancient Greece is a means of achieving the aesthetic ideal of the body whose physical beauty and godlike athleticism is put at the centre of art. The emphasis on human body recedes during the Middle Ages and regains power during the Renaissance. Nowadays, the beautiful body is a cult advocated by the whole advertising industry. It is the foremost merit of celebrities who direct, formally or informally, the trends in fashion and entertainment industry, brainwashing the mind of billions and shepherding consumption to the satisfaction of "attaining" beautiful body as an instrument of social interaction. The body has turned into a reactive of the system of demonstrative consumption which correlates to the level of social and economic development of the respective society.

In tribal (clan) societies, food is a scarce commodity and its regular possession is a marker of wealth, body fats being the physical manifestation of the same marker. In the period of early capitalism, when the vast majority of people is hungry, wealth was measured by the size of the the waistline - the more substantial the size, the higher the status of the trader. The same trend dominates the 19th century in
Germany, Great Britain and USA. The bodily perfection in Russia was incarnated in women with solid proportions.

Once hunger ceased to persist as a major concern for the countries of the first and the second world, the cultural norm drastically changed. By asserting lean and skinny body as a beauty standard, the sated majority demonstrates consumption of selected, hard-toget expensive food as contrasted with the highfat diet of common people that makes them obese and drooping. Espousing the ideals of bodily perfection through sports and physical activity in the postmodern mass cultural age is a matter of principle, self-assertion, affirming pleasure and a challenge at the expense of the respective sacrifice - money, diet, strict time management and workout sessions held in special places. The athletic figure is symbolic of high culture - on one hand, keeping the body in as good shape as possible means that the body owner has ample of time and other resources, including intelligence. The rich are more likely to find time for both work and active leisure than those who follow the monotonous humdrum between going to work and going to bed, paying little or no heed of their appearance due to lack of resources, lack of interest or mere neglect. This is why athletic figure and awareness in favour of regular physical activity are signs of ability and success whereas poor physical condition and diseases points to low income and low culture. The new age provoked the "epidemic" of body weight regulation and by the end of the 80 s the production of the respective products reached 33 billion dollars in the USA. The new ideal stimulated economy by a system of facilities, equipment, simulators, guidebooks and educational materials, diet food, plastic surgery, etc. representing a brand new market. By the end of the century, $45 \%$ of women and $33 \%$ of men in the USA have actively considered plastic surgery as an option to improve their body, particularly their face. (4, 138). And the role of the face in communicating with other people is key. It is a body part which is freely "accessible" and unveiled in most cultures. Civilizations throughout history have used forms of facial beauty care. Today, this perceived need has developed a massive market of cosmetics (including skin care creams, lotions, powders, make-up, lipsticks, eyeliner, eye-shadow, eyelashes, cosmetic and plastic surgery, correcting agents, etc.) that kindles firm and permanently increasing interest despite high pricing. 
The condition of the body carries a sort of "specialized" information to the opposite sex. Although men and women share similar attitudes to their bodies, they follow different models. Baudrillard suggests two terms phryneism $^{4}$ for the female model and athleticism for the male model. According to Baudrillard, beauty is no longer an effect of nature or a supplement to moral virtues. Being beautiful has become a religious imperative and a primary form of capital $(2,136)$.

The colour and appearance of the skin have been symbolic and meaningful in communication since ages. Skin is another sign and barometer of prestige. Black race is associated with slavery. But since blacks themselves see lighter skin as a marker of higher social status the business of expensive skin whitening surgery has proliferated. In many societies, suntan and darker complexion suggest working outdoors. Workers themselves used to protect themselves from the sun by putting head scarves because pale (fair) complexion was considered highly desirous for women and advantageous for men. The 20th century reverses the paradigm, especially when many of the "wage slave" occupations moved indoors. Pallor was no longer a badge of nobility, on the contrary - it became a signal of health problems. Bronze skin, in turn, started to indicate wealthy, healthy and luxurious lifestyle. In the 1920s, sun tanning has become a new fashion on the French Riviera (3) and a must for all romantic characters in the blooming film-industry. Despite the overwhelming suntan surge throughout Europe in the 30s, darker complexion remained an indicator of lower class. Nowadays (mostly in Northern countries, especially in the winter season), the bronze tan signifies ability to afford overseas holiday. The usual meaning conveyed by suntan complexion, namely, sufficient time and money to spend on physical exercise and outdoors entertainment, is charged with another quality - eroticism. Even in multicultural societies like the USA, Brazil, Great Britain and France, the blacks, Arabs and the people with coloured skin have been reckoned as more erotic, sexual and passionate. These modifications of the sign steer the desire to its deliberate attainment - by means of tanning beds (solarium), sun bathing with sunscreen lotions, colour correction creams,

\footnotetext{
${ }^{4} \mathrm{By}$ the name of the Greek courtesan Phryne who was prosecuted under charges of impiety. To avoid unfavourable verdict despite the brilliant orator skills of her defender, she bared her breasts before the judges and they decided to acquit her startled by her beauty.
}

gels and balsams, self-tanners, leading to a real market explosion kept up not only by the women. Moreover, the Medical enlightenment incites fear of skin cancer which motivates the market of sun block products to prosper even more. Eventually, values score a new revision - beautiful is everything that is beautiful at present, provided that it will not a have negative effect tomorrow. Thus, sunless tanning has become safer than sun exposure even when the intensity of sun rays is not harmful.

Hair is a fundamental erotic symbol. The signal "I don't feel like having sex" is conveyed by covering (wrapping) the hair or pulling it back, the contrary action, respectively, is elicited by multiplying the symbol (long, loose, flowing hair, freely cascading around the face and shoulders). But the interpretation of this code is also quite ambiguous and is affected by factors such as religion, culture, mindset, fashion and emancipation. In orthodox churches, it is accepted that women should wear their hair covered or gathered, in many cultures women make their hair (and faces) even harder to see or touch, yet, while in most religions the lack of hair (including tonsure as a traditional practice in Catholicism) is a sign of abstinence, austerity and self-denial, long hair in Orthodox clergymen is an asexuality marker.

Canons and fashions rise and fall, but for decades on end, the associated market invariably grows and expands. One of the favourable conditions is again the medical enlightenment and its credo - beautiful hair is healthy hair. The function of cosmetics thus becomes highly diversified and is no longer reduced to washing - nowadays it promises stronger, healthier-looking, thicker and fuller hair. And since factories produce products, markets sell hope, advertising becomes increasingly resourceful, captivating and global. Baldness has been a scourge of the male scalp for almost the entire 20th century, but during the 90s, very short haircut (or shaved hair design) was perceived as a sign of masculinity and baldness ceased to be a problem, on the contrary, the trendy hairstyle forced men to heat the blades and try the shaving razor on their once cherished long hair. But fashion changed again and today's hit is to have hair, preferably fixed in flipped up forelock and this tendency has quickly resurrected and multiplied the market of services and products maintaining hair loss medical treatments and cosmetics, medications, transplantation, etc. The promises of miraculous effects proliferate although there 
is still no evidence of reducing the number of baldheaded men as a result of any medical or cosmetic treatment. The list of communicative and marketing "powers" of hair is to be continued. On one hand, unrestrained long hair is a signal of unrestrained sexuality, while office-appropriate tight buns subdue sexual appeal. Long hair is also a symbol of maidenhood, innocence and purity. During the 60 s and the uprising of the flower children (the hippies), loose, long open hair symbolized radical resistance and rebellion against bourgeois values, but since emancipation has often been associated with hairstyle, women's short hairstyles which used to denote inaccessibility, are now predominant among lovers of freedom and looseness. During the last half century, body hair has been an issue because according to the cultural code in European and North American countries it is socially unacceptable for women to be hairy. This precondition has soon after branched out the market of hair removal products and treatments. Feminists see it as direct form of male's control and call for the "natural" body look as a counter-movement ("hairy is not scary") protesting against the supremacy of male's ideals. Besides, there is an increasing number of men who opt for the same grooming rights as women, including total body hairremoval, which raises the question who is the real dictator. After all, fashion always follows both formal and informal opinion leaders, what is more, global fashion knows no borders - the FIFA world championship held in Brazil in the summer of 2014 set up a trend of fashionable footballer haircuts and heavily tattooed bodies which practically pervaded the market for practically a few days and affecting youngsters and adults alike. From discreet erotic tattoos inked on secret parts of the body to treating the body as canvas of one's personal experience and story, today tattoos are in vogue, a mania and a badge, which has, subsequently, given rise to a grandiose industry for equipment, ink, faster healing drugs and aftercare treatments. What is striking is that while in a number of foreign cultures tattoos are body decoration, a sign of self-identification as belonging to certain group, or a threating signal against enemies, and their symbolic meaning directs to the others like coded advertising, in European culture it was a patent feature of sailors, criminals, prisoners and certain non-formal subculture groups only thirteen years ago.

This paper and its preceding part shed only a cursory glance at the physical and social body in the context of their respective markets and serve as a framework of further exploration and conclusions. Analyzing physical and social dominants in body clothing (the communication system of clothes) might raise even more thought-provoking issues for discussion, but this remains in the agenda for future research work.

\section{REFERENCES}

1. Сапарев, O. 1994. Литературната комуникация. П.: П. Хилендарски.

2. Baudrillard, J. 1998. The Consumer Society: Myths and Structures. L.: Sage.

3. Ильин, И. 2000. Поведение потребителей. С.П.: Питер.

4. Schiffman, L., L. Kanuk. 2009. Consumer Behaviour. 10th ed. S.: Prentice Hall PTR 